\title{
Health Intervention Impact Assessment on Glycemic Status of Diabetic Patients
}

\author{
He mant Mahajan ${ }^{1, *}$, Te jashri Kambali ${ }^{2}$, Manish Chokhandre ${ }^{3}$, Amod Borle ${ }^{1}$, Maya Padvi ${ }^{2}$ \\ ${ }^{1}$ Department of Community Medicine, RCSM GMC Kolhapur, Maharashtra, India \\ ${ }^{2}$ Department of Community Medicine, TN Medical College, Mumbai, Maharashtra, India \\ ${ }^{3}$ Department of Pediatrics, TN Medical College, Mumbai, Maharashtra, India
}

\begin{abstract}
Diabetes has been proved to be the leading cause of morbidity and mortality in developed countries, and is gradually emerg ing as an important health problem in developing countries as well. Diabetes, an iceberg disease could be described as the 'sleeping snake'- which bites when it wakes up. Diabetics, who are joyfully moving in and around us in the society, who are really not aware of the possible catastrophic end results of harbouring this 'sleeping snake'. This study was carried out to assess the impact of health intervention on life style, self care practices and Glycemic status ofDiabetic patients. A cross-sectional study was conducted at Shivaji Nagar urban slum which is a field practice area of Department of Preventive and Social Medicine; of TN Medical College Mumbai, India. Diabetic patients above 40 years of age were included in this study. The information was gathered by personal interview using semi-structured questionnaire. The collected data was numerically coded and entered in Microsoft Excel 2007 and then transferred to SPSS version 15.0 Added data was analysed with appropriate test and results were obtained. Out of 300 subjects $183(61 \%)$ were males, $146(48.7 \%)$ patients were in the age group of 51-60. Before intervention 178 (59.3\%) patients' had Body mass index (BMI) $>25 \mathrm{~kg} / \mathrm{m}^{2}$ and they had poor control over blood sugar. Significant improvement in life style, self care practices; illness perception and Glycemic status of patients were seen after health intervention. People have to be educated through mass media about Diabetes and its risk factors like consumption of food having high Glycemic index, alcohol etc. People have to be educated on the importance of regular physical exercises and should be encouraged to do the same.
\end{abstract}

Keywords Type 2 Diabetes, Glycemic Status, Health Intervention, Urban Slum

\section{Introduction}

After combating gigantic problem of communicable diseases, like many developing nations India is also facing the new problem of chronic non commun icable diseases such as diabetes because of rapid urbanization and adaptation of modern life styles. After hypertension, Diabetes mellitus (DM) is one of the most daunting challenges posed by chronic non-communicable disease. Although many preventive and control measures are available, prevalence of Diabetes is rising and it has become a global problem causing enormous morbidity and mortality in all developed as well as developing countries. In 2000, according to the World Health Organization, at least 171 million people worldwide suffer from diabetes, or $2.8 \%$ of the total population. The prevalence of type 2 diabetes mellitus is steadily increasing world wide with an estimated 366 million patients in 2030[1]. Type $2 \mathrm{DM}$ is the commonest form of diabetes globally as well as in India. The prevalence of

* Corresponding author:

hemant.mahajan.84@gmail.com (Hemant Mahajan)

Published online at http://journal.sapub.org/diabetes

Copyright (C) 2012 Scientific \& Academic Publishing. All Rights Reserved diabetes has shown increasing trend in the last three decades in India. The number of people with diabetes in India currently around 40.9 million is expected to rise to 69.9 million by 2025 unless urgent preventive steps are taken[2]. The present study was carried out keeping in view the illness perceptions, lifestyle and self care adopted by the patients after diagnosis and to identify the area that needs urgent attention to modify the life style and promote self care practices among them. Objective of the study was to improve the health and blood sugar control in type 2 diabetes patients by giving health education, dietary advice and encouraging them for regular blood sugar monitoring and physical exercise.

\section{Material and Methodology}

The study was conducted at Shivaji Nagar urban slum which is a field practice area of Department of Preventive and Social Medicine, of TN Med ical College,Mu mbai,India. This is situated at an eastern suburb of Mumbai which comes under the jurisdiction of $\mathrm{M}$ East Ward of Municipal Corporation of Greater Mumbai, India. The population of Shivaji Nagar consists of people who have migrated from different parts of India, mainly from Uttar Pradesh, Bihar, 
West Bengal, Madhya Pradesh, Andhra Pradesh and Tamil Nadu. They have migrated to Mu mbai in search of job. Study population was selected from type 2 diabetic patients of age 40 years $\&$ above.

Total Population of Study Area $=1,22,000$.

According to National Family Health Survey data 2005 -06 the population of more than 40 years is around $25.8 \%$.

Population of more than 40 years would be around 31476 .

Prevalence of Diabetes $>40$ years in an urban slum of Mumbai is $9.3 \%[3]$.

Expected number of diabetic patients in study population $=2928$

Taking $10 \%$ of expected patients $=292.8$ Sample size $(\mathrm{n})$ $=/>293$. By taking, inclusion and exclusion criteria into consideration, total 300 known Diabetic patients were selected by employing simple random sampling method.

This study was conducted in the following 6 phases-

1) Preparatory Phase: October 2009 to December 2009 (3 months)

2) Phase of rapid survey: January 2010 to March 2010 (3 Months)

2) Phase of Pre Intervention Data Collection: April 2010 to June 2010 (3 months)

3) Intervention Phase: July 2010 to June 2011 (1 year)

4) phase of Post Intervention Data Collection: July 11 to September 2011 (3 months)

5) Phase of Data Analysis: October2011 (1 month)

6) Documentation Phase: November 2011 to December 2011(1 month)

Semi structured interview schedule was constructed relevant to the study. This interview schedule was tested by pilot study on 25 diabetic patients attending geriatric clinic in Urban Health Center (UHC). Appropriate changes were done based on pilot study and the interview schedule was finalized. Voluntary consent form was prepared in English, Hindi and Marathi. Home visits were done between 10.00 am to $4.00 \mathrm{pm}$ on working days. The information was collected about various socioeconomic factors, illness perceptions, family history, addiction, duration of disease, exercise, complications, as sociated disorders, life style, self care etc. on preformed, pre tested interview schedule by investigator himself. Height, Weight and Blood pressure, Blood sugar were measured by using appropriate technique. Participants were followed up for 12 months from Ju ly 2010 to June 2011 for intervention. Each diabetic patient had been given one individual number like $1 / 2010$ to $300 / 2010$. Regular follow up and monitoring of weight, blood pressure, blood sugar and medical history was maintained in that register.

Formation of batches and fixing of timing: Total 300 patients were grouped in to 10 batches of 30-35 patients. All the participants were told and motivated to attend the health education session on a particular day depending on the feasibility of all the patients of a particular batch. Such health education sessions were headed by two doctors and conducted every week in morning hour from 10:15 am to 11:00 a m. The health education was given in local language by the doctor.

Intervention measures included:

1) Medical treatment: Participants were followed up fortnightly in Urban Health Center. In follow up visits complete physical examination including weight, blood pressure, and blood sugar were done and treated accordingly. Patients having complications were re ferred to higher centers for expert's opinion.

2) Health Education: Health education was given monthly during follow up visits at Urban Health Centre (UHC). Health education was given in group and in single. In health education patients were given basic information about diabetes and its complications and how to control blood sugar and prevent its complications. Patients were also given information about hypoglycaemia, how to prevent it and what to do in hypoglycaemic episode.

3) Dietary Advice: Dietary Advice was done during follow up visits at UHC with the help of dietician. In dietary advice patients were given information about different types of foods which are harmful or beneficial in diabetes and spacing of meals.

4) Blood Sugar examination: Blood sugar (fasting and post prandial) were monitored once in a 3 months in the laboratory of Urban Health Center.

5) Eye check up: Each patient motivated to come for their eye check-up which was done by Ophthalmo logist.

Appropriate scoring was done for illness perception, life style factors and self care factors in both pre intervention and post intervention phases. The collected data was numerically coded and entered in Microsoft Excel 2007 and then transferred to SPSS version 15.0 Added data was analyzed with appropriate test like Chi-square test, ' $t$ ' test to see the association between various parameter, with $p$ value 0.05 considered as significant.

\section{Results}

Total 300 diabetic subjects were examined consisting of $183(61 \%)$ males and $117(39 \%)$ females. Majority of patients $146(48.7 \%)$ were in the age group of 51-60 years with mean age of patients was 51.6 years. $188(62.7 \%)$ subjects were from Socio-economic class III, IV, V (according to Modified Prasad classification). Most of the patients 135 (45\%) were either une mployed or unskilled, 162 (54\%) were illiterate or just completed primary education and $34.3 \%$ patients had family history of diabetes.

Table 1 shows, total $178(59.3 \%)$ had Body mass index (BMI) more than or equal to $25 \mathrm{~kg} / \mathrm{m}^{2}$ and had poor control over fasting and post-prandial blood sugar. 
Table 1. Association of Body mass index (BMI) and Blood sugar (n- 300)

\begin{tabular}{|c|c|c|c|c|c|c|}
\hline \multirow{2}{*}{ BMI (Pre-intervention) } & \multicolumn{3}{|c|}{ Fasting Blood Sugar (FBS) } & \multicolumn{3}{c|}{ Post prandial Blood Sugar (PPBS) } \\
\cline { 2 - 7 } & $<110 \mathrm{mg} / \mathrm{dl}$ & $110-140 \mathrm{mg} / \mathrm{dl}$ & $>140 \mathrm{mg} / \mathrm{dl}$ & $<110 \mathrm{mg} / \mathrm{dl}$ & $110-140 \mathrm{mg} / \mathrm{dl}$ & $>140 \mathrm{mg} / \mathrm{dl}$ \\
\hline $\begin{array}{c}\text { Underweight \& normal, BMI }< \\
25 \mathrm{~kg} / \mathrm{m}^{2}(122)\end{array}$ & $67(22.3 \%)$ & $45(15 \%)$ & $10(3.3 \%)$ & $60(20 \%)$ & $37(12.3 \%)$ & $25(8.3 \%)$ \\
\hline $\begin{array}{c}\text { Overweight/Preobese, BMI } \\
25-29.99 \mathrm{~kg} / \mathrm{m}^{2}(107)\end{array}$ & $25(8.3 \%)$ & $27(9 \%)$ & $55(18.3 \%)$ & $28(9.3 \%)$ & $40(13.3 \%)$ & $39(13 \%)$ \\
\hline $\begin{array}{c}\text { Obese, BMI } 30 \mathrm{~kg} / \mathrm{m}^{2} \text { and } \\
\text { more }(71)\end{array}$ & $10(3.3 \%)$ & $21(7 \%)$ & $40(13.3 \%)$ & $11(3.7 \%)$ & $28(9.3 \%)$ & $32(10.7 \%)$ \\
\hline $\begin{array}{c}\text { Chi-square value } \\
\text { Association }\end{array}$ & \multicolumn{3}{|c|}{$\mathrm{x}^{2}-72.6 ; \mathrm{df}-4 ; \mathrm{p}<0.01$} & \multicolumn{2}{c|}{$\mathrm{x}^{2}-28.6 ; \mathrm{df}-4 ; \mathrm{p}<0.01$} \\
\hline
\end{tabular}

Table 2. Modification factors in pre and post intervention phase

\begin{tabular}{|c|c|c|c|c|c|}
\hline $\begin{array}{c}\text { LIFE STYLE } \\
\text { FACT ORS }\end{array}$ & Pre-intervention & Post-intervention & $\begin{array}{c}\text { SELF CARE } \\
\text { FACT ORS }\end{array}$ & Pre-intervention & Post-intervention \\
\hline Cut down sweets & $213(71 \%)$ & $251(83.7 \%)$ & $\begin{array}{c}\text { Taking medicines } \\
\text { regularly }\end{array}$ & $185(61.7 \%)$ & $257(85.7 \%)$ \\
\hline Cut down oil & $94(31.3 \%)$ & $153(51 \%)$ & $\begin{array}{c}\text { Regular blood sugar } \\
\text { monitoring }\end{array}$ & $216(72 \%)$ & $267(89 \%)$ \\
\hline $\begin{array}{c}\text { Intake of fruits \& } \\
\text { vegetables in diet }\end{array}$ & $84(28 \%)$ & $180(60 \%)$ & $\begin{array}{c}\text { Complianceto } \\
\text { prescribed dose }\end{array}$ & $166(56.3 \%)$ & $228(76 \%)$ \\
\hline $\begin{array}{c}\text { Doing regular } \\
\text { physical exercise }\end{array}$ & $71(23.7 \%)$ & $140(46.7 \%)$ & $\begin{array}{c}\text { Taking insulin inj. by } \\
\text { self }(\mathrm{n}-45)\end{array}$ & $18(40 \%)$ & $27(60 \%)$ \\
\hline $\begin{array}{c}\text { No addiction } \\
\text { urine sugar at home }\end{array}$ & $160(53.3 \%)$ & $40(13.3 \%)$ & $108(36 \%)$ \\
\hline $\begin{array}{c}\text { Carrying medication } \\
\text { regularly when } \\
\text { going out of station }\end{array}$ & $100(33.3 \%)$ & $135(45 \%)$ & $\begin{array}{c}\text { Carrying sugar/biscuits } \\
\text { to prevent } \\
\text { hypoglycaemic spells }\end{array}$ & $12(4 \%)$ & $39(13 \%)$ \\
\hline $\begin{array}{c}\text { Not eat ing sweets } \\
\text { during ceremonies } \\
\& \text { festivals }\end{array}$ & $153(51 \%)$ & $233(77.7 \%)$ & Care of feet & $80(26.7 \%)$ & $138(46 \%)$ \\
\hline $\begin{array}{c}\text { Family members } \\
\text { co-operative in } \\
\text { giving correct foods } \\
\text { at correct time }\end{array}$ & $209(69.7 \%)$ & $243(81 \%)$ & Carrying diabetic card & $28(9.7 \%)$ & $100(33.3 \%)$ \\
\hline
\end{tabular}

Table 3. Effect of health intervention on life style factors, self care practices and illness perception

\begin{tabular}{|c|c|c|c|c|c|c|}
\hline \multicolumn{2}{|c|}{ Effect of intervention } & Pre-intervention & Post-intervention & Chi-square value & p -value & Association \\
\hline \multirow{6}{*}{$\begin{array}{l}\text { Life-style } \\
\text { factors } \\
\text { score }\end{array}$} & \multirow{2}{*}{ Some $(0-2)$} & 77 & 55 & \multirow{6}{*}{20.5} & \multirow{6}{*}{$<0.01$} & \multirow{6}{*}{$\begin{array}{l}\text { Significant } \\
\text { difference }\end{array}$} \\
\hline & & $25.70 \%$ & $18.30 \%$ & & & \\
\hline & \multirow{2}{*}{ Moderate (3-5) } & 179 & 156 & & & \\
\hline & & $59.70 \%$ & $52 \%$ & & & \\
\hline & \multirow{2}{*}{ Major (6-8) } & 44 & 89 & & & \\
\hline & & $14.70 \%$ & $29.70 \%$ & & & \\
\hline \multirow{6}{*}{$\begin{array}{l}\text { Self care } \\
\text { factors } \\
\text { score }\end{array}$} & \multirow{2}{*}{ Some $(0-2)$} & 70 & 45 & \multirow{6}{*}{14.6} & \multirow{6}{*}{$<0.01$} & \multirow{6}{*}{$\begin{array}{l}\text { Significant } \\
\text { difference }\end{array}$} \\
\hline & & $23.30 \%$ & $15 \%$ & & & \\
\hline & \multirow{2}{*}{ Moderate (3-5) } & 165 & 152 & & & \\
\hline & & $55 \%$ & $50.70 \%$ & & & \\
\hline & \multirow{2}{*}{ Major (6-8) } & 65 & 103 & & & \\
\hline & & $21.70 \%$ & $34.30 \%$ & & & \\
\hline \multirow{4}{*}{$\begin{array}{l}\text { Illness } \\
\text { perception } \\
\text { score }\end{array}$} & \multirow{2}{*}{ Poor $(0-2)$} & 250 & 187 & \multirow{4}{*}{32.4} & \multirow{4}{*}{$<0.01$} & \multirow{4}{*}{$\begin{array}{l}\text { Significant } \\
\text { difference }\end{array}$} \\
\hline & & $83.30 \%$ & $62.30 \%$ & & & \\
\hline & \multirow{2}{*}{ Better (3-5) } & 50 & 113 & & & \\
\hline & & $16.70 \%$ & $37.70 \%$ & & & \\
\hline
\end{tabular}


Life style factors and self care factors had given scores. Subjects having 0-2, 3-5, 6-8 score were categorized into 'some', 'moderate' and 'major' category respectively. Similarly illness perception of diabetic patients were decided based on five domains i.e. cause, timeline, cure-control, symptoms and consequences. Patients having scores of 0-2 and 3-5 were categorized into 'poor' and 'better' respectively. Table 2 and 3 , show significant improvement in life style factors, self care adoption and illness perception after intervention.

After assessing illness perception based on cause, timeline, cure-control, symptoms and consequences, it was found that only $13.7 \%$ subjects knew that diabetes occurred due to metabolic mechanism. While majority $(35.3 \%)$ of subjects used to believe that it occurred due to high sugar intake in diet. About $18.7 \%$ subjects said that stress was aetiology of diabetes. Around $27 \%$ of subjects said that diabetes is temporary illness and it will resolve one day due to the medications they are taking. While 39.3\% subjects admitted that there is no cure for diabetes and it is permanent illness. $36.3 \%$ subjects said that excess thirst, appetite and increased frequency of micturation are main symptoms of diabetes. While $8.7 \%$ said tingling \& numbness is the main symptom of diabetes mellitus. $18 \%$ subjects said that diabetes can be cured with medicines while $31.3 \%$ knew that it can't be cured but it can be controlled. Majority i.e.73.3\% subjects had no idea about complications that could occur due to diabetes mellitus. Few patients admitted that ophthalmic and renal diseases can occur as a complication and 6\% said foot ulcers can occur if blood sugar is not kept under control.

Table 4 shows $104(34.7 \%)$ of the patients who were not taking treatment properly because of many reasons; most common was the feeling of relief in $50(16.7 \%)$ followed by too many medicines in $35(11.7 \%)$ and higher cost of med icines $20(6.7 \%)$.

Table 5 and 6 shows patients having 'some' life style factors score, self care score and 'poor' illness perception score had poor control over both fasting and post prandial blood sugar. Significant improvement in blood sugar control was seen after health intervention when life style, self care practices and illness perception were improved.

Table 4. Reasons for taking irregular treatment

\begin{tabular}{|l|l|}
\hline Reason & Frequency \\
\hline Feeling of relief & $50(16.7 \%)$ \\
\hline Too many medicines & $35(11.7 \%)$ \\
\hline High cost & $20(6.7 \%)$ \\
\hline Less money & $18(6 \%)$ \\
\hline Going out of station & $7(2.3 \%)$ \\
\hline More number of doses & $6(2 \%)$ \\
\hline Family matters & $4(1.3 \%)$ \\
\hline Total & $104(34.7 \%)$ \\
\hline$*$ Overlapping of responses was there. & \\
\hline
\end{tabular}

Table 5. Effect of health intervention on fasting blood sugar (FBS) and Post-Prandial blood sugar (PPBS)

\begin{tabular}{|c|c|c|c|c|c|c|}
\hline \multicolumn{2}{|c|}{ Effect of intervention on Blood sugar level } & $\mathrm{N}$ & Mean & paired t- test & $\mathrm{p}$-value & Difference \\
\hline \multirow{2}{*}{ FBS } & Pre-intervention & 300 & $176.78 \mathrm{mg} / \mathrm{dl}$ & \multirow{2}{*}{8.59} & \multirow{2}{*}{$<0.01$} & \multirow{2}{*}{ Significant } \\
\hline & Post-intervention & 300 & $138.43 \mathrm{mg} / \mathrm{dl}$ & & & \\
\hline \multirow{2}{*}{ PPBS } & Pre-intervention & 300 & $223.71 \mathrm{mg} / \mathrm{dl}$ & \multirow{2}{*}{6.13} & \multirow{2}{*}{$<0.01$} & \multirow{2}{*}{ Significant } \\
\hline & Post-intervention & 300 & $190.31 \mathrm{mg} / \mathrm{dl}$ & & & \\
\hline
\end{tabular}


Table 6. Association of life style factors score; self care adoption practices score and illness perception with blood sugar

\begin{tabular}{|c|c|c|c|c|c|c|}
\hline \multirow{2}{*}{$\begin{array}{l}\text { Life style factor score } \\
\text { (Pre-in terven tion) }\end{array}$} & \multicolumn{3}{|c|}{ Fasting Blood Sugar in $\mathrm{mg} / \mathrm{dl}(\mathrm{n}-300)$} & \multicolumn{3}{|c|}{ Post Prandial Blood Sugar in $\mathrm{mg} / \mathrm{dl}(\mathrm{n}-300)$} \\
\hline & $<110$ & $110-140$ & $>140$ & $<140$ & $140-180$ & $>180$ \\
\hline Some (77) & $13(4.3 \%)$ & $(4 \%)$ & $52(17.3 \%)$ & $16(5.3 \%)$ & $16(5.3 \%)$ & $45(15 \%)$ \\
\hline Moderate (179) & $59(19.7 \%)$ & $73(24.3 \%)$ & $47(15.7 \%)$ & $55(18.3 \%)$ & $82(27.3 \%)$ & $42(14 \%)$ \\
\hline Major (44) & $30(10 \%)$ & $8(2.7 \%)$ & $6 \quad(2 \%)$ & $28(9.3 \%)$ & $7(2.3 \%)$ & $9(3 \%)$ \\
\hline Chi-square test & \multicolumn{3}{|c|}{ Chi-square value - $68.5 ; \mathrm{df}-4 ; \mathrm{p}<0.01$} & \multicolumn{3}{|c|}{ Chi-square value -54.1 ; df- $4, \mathrm{p}<0.01$} \\
\hline \multirow{2}{*}{$\begin{array}{l}\text { Life style factor score } \\
\text { (Post-intervention) }\end{array}$} & \multicolumn{3}{|c|}{ Fasting Blood Sugar in $\mathrm{mg} / \mathrm{dl}(\mathrm{n}-300)$} & \multicolumn{3}{|c|}{ Post Prandial Blood Sugar in $\mathrm{mg} / \mathrm{dl}(\mathrm{n}-300)$} \\
\hline & $<110$ & $110-140$ & $>140$ & $<140$ & $140-180$ & $>180$ \\
\hline Some (55) & $7 \quad(2.3 \%)$ & $8(2.7 \%)$ & $40(13.3 \%)$ & $6(2 \%)$ & $11(3.7 \%)$ & $38(12.7 \%)$ \\
\hline Moderate (156) & $46(15.3 \%)$ & $60(20 \%)$ & $50(16.7 \%)$ & $43(14.3 \%)$ & $66(22 \%)$ & $47(15.7 \%)$ \\
\hline Major (89) & $52(17.3 \%)$ & $27(9 \%)$ & $10(3.3 \%)$ & $57(19 \%)$ & $24(8 \%)$ & $8(2.7 \%)$ \\
\hline Chi-square test & \multicolumn{3}{|c|}{ Chi-square value $-69.2 ;$ df- $4, p<0.01$} & \multicolumn{3}{|c|}{ Chi-square value -80.1 ; df- $4, \mathrm{p}<0.01$} \\
\hline \multirow{2}{*}{$\begin{array}{l}\text { Self care factors score } \\
\text { (Pre-in tervention) }\end{array}$} & \multicolumn{3}{|c|}{ Fasting Blood Sugar in mg/dl (n-300) } & \multicolumn{3}{|c|}{ Post Prandial Blood Sugar in $\mathrm{mg} / \mathrm{dl}(\mathrm{n}-300)$} \\
\hline & $<110$ & $110-140$ & $>140$ & $<140$ & $140-180$ & $>180$ \\
\hline Some $(70)$ & $8 \quad(2.7 \%)$ & $20(6.7 \%)$ & $42(14 \%)$ & $7(2.3 \%)$ & $14(4.7 \%)$ & $49(16.3 \%)$ \\
\hline Moderate (165) & $50(16.7 \%)$ & $55(18.3 \%)$ & $60(20 \%)$ & $52(17.3 \%)$ & $74(24.7 \%)$ & $39(13 \%)$ \\
\hline Major (65) & $44(14.7 \%)$ & $18(6 \%)$ & $3(1 \%)$ & $40(13.3 \%)$ & $17(5.7 \%)$ & $8(2.7 \%)$ \\
\hline Chi-square test & \multicolumn{3}{|c|}{ Chi-square value $-62.2 ; \mathrm{df}-4, \mathrm{p}<0.01$} & \multicolumn{3}{|c|}{ Chi-square value $-80.9 ;$ df- $4, p<0.01$} \\
\hline \multirow{2}{*}{$\begin{array}{l}\text { Self care factors score } \\
\text { (Post-intervention) }\end{array}$} & \multicolumn{3}{|c|}{ Fasting Blood Sugar in $\mathrm{mg} / \mathrm{dl}(\mathrm{n}-300)$} & \multicolumn{3}{|c|}{ Post Prandial Blood Sugar in $\mathrm{mg} / \mathrm{dl}(\mathrm{n}-300)$} \\
\hline & $<110$ & $110-140$ & $>140$ & $<140$ & $140-180$ & $>180$ \\
\hline Some (45) & $6(2 \%)$ & $9(3 \%)$ & $30(10 \%)$ & $6(2 \%)$ & $7(2.3 \%)$ & $32(10.7 \%)$ \\
\hline Moderate (152) & $39(13 \%)$ & $52(17.3 \%)$ & $53(17.7 \%)$ & $30(10 \%)$ & $68(23.7 \%)$ & $54(18 \%)$ \\
\hline Major (103) & $60(20 \%)$ & $34(11.3 \%)$ & $9(3 \%)$ & $70(23.3 \%)$ & $26(8.7 \%)$ & $7(2.3 \%)$ \\
\hline Chi-square test & \multicolumn{3}{|c|}{ Chi-square value $-62.4 ; \mathrm{df}-4, \mathrm{p}<0.01$} & \multicolumn{3}{|c|}{ Chi-square value $-103.5 ;$ df- $4, p<0.01$} \\
\hline \multirow{2}{*}{$\begin{array}{c}\text { Illness perce ption } \\
\text { s core(Pre-intervention) }\end{array}$} & \multicolumn{3}{|c|}{ Fasting Blood Sugar in mg/dl (n-300) } & \multicolumn{3}{|c|}{ Post Prandial Blood Sugar in $\mathrm{mg} / \mathrm{dl}(\mathrm{n}-300)$} \\
\hline & $<110$ & $110-140$ & $>140$ & $<140$ & $140-180$ & $>180$ \\
\hline Poor (250) & $79(26.3 \%)$ & $76(25.3 \%)$ & $95(31.7 \%)$ & $64(21.3 \%)$ & $97(32.3 \%)$ & $89(29.7 \%)$ \\
\hline Better (50) & $23(7.7 \%)$ & $17(5.7 \%)$ & $10(3.3 \%)$ & $35(11.7 \%)$ & $8(2.7 \%)$ & $7(2.3 \%)$ \\
\hline Chi-square test & \multicolumn{3}{|c|}{ Chi-square value $-6.5 ;$ df- $2, p-0.03$} & \multicolumn{3}{|c|}{ Chi-square value $-37.2 ;$ df- $2, p<0.01$} \\
\hline \multirow{2}{*}{$\begin{array}{c}\text { Illness perception } \\
\text { s core(Post-in terven tion) }\end{array}$} & \multicolumn{3}{|c|}{ Fasting Blood Sugar in $\mathrm{mg} / \mathrm{dl}(\mathrm{n}-300)$} & \multicolumn{3}{|c|}{ Post Prandial Blood Sugar in $\mathrm{mg} / \mathrm{dl}(\mathrm{n}-300)$} \\
\hline & $<110$ & $110-140$ & $>140$ & $<140$ & $140-180$ & $>180$ \\
\hline Poor (187) & $33(11 \%)$ & $61(20.3 \%)$ & $93(31 \%)$ & $34(11.3 \%)$ & $71(23.7 \%)$ & $82(27.3 \%)$ \\
\hline Better (113) & $72(24 \%)$ & $34(11.3 \%)$ & $7 \quad(2.3 \%)$ & $72(24 \%)$ & $30(10 \%)$ & $11(3.7 \%)$ \\
\hline Chi square test & \multicolumn{3}{|c|}{ Chi-square value - $82.9 ;$ df- $2 ; p<.0 .01$} & Chi-square & ue - $70.5 \%$; & $2 ; \mathrm{p}<.0 .01$ \\
\hline
\end{tabular}

\section{Discussion}

The present community based descriptive epidemio logical interventional study was conducted at an urban slum in Mumbai, India which is a field practice area of Department of Preventive and Social Medicine, TN Medical College, Mumbai, India. It was conducted during the period of October 2009 to September 2011, selecting 300 known cases of type 2 diabetes by employing simple random sampling method.

Total 300 diabetic subjects were examined with mean age of 51.6years. In present study $155(64.5 \%)$ of the subjects had BMI more than 25. Mean BMI was $25.64(\mathrm{SD}=4.03)$ which is above the normal BMI. In a study conducted by Kapur et al[4], the multivariate-adjusted hazard ratios were 1.15 for normal-weight inactive, 3.68 for overweight active, 4.16 for overweight inactive, 11.5 for obese active, and 11.8 for obese inactive participants.

In this study both fasting and post-prandial (PP) blood sugar we re high (Fasting $>140 \mathrm{mg} / \mathrm{d} 1, \mathrm{PP}>200 \mathrm{mg} / \mathrm{dl}$ ) in 145 $(48.3 \%)$ and $161(53.7 \%)$ of subjects respectively. Obesity was found to be significantly associated with both high 
fasting \& Post-Prandial blood sugar levels. Though patients' had diabetes for more than a year still the blood sugar was not under control. R Gupta et al in his study[5] had similar results that BMI correlate significantly with fasting blood sugar, and negatively with physical activities. There was a significant increase in fasting blood sugar with increasing BMI. Any physical activity was inversely related to BMI. A steep increase in the prevalence of diabetes was observed in patients having BMI $>25 \mathrm{~kg} / \mathrm{m}^{2}$.

In this study it was found that only $28 \%$ subjects had increased consumption of vegetables and fruits in diet, $23.7 \%$ were doing regular exercises and $33.3 \%$ had no addictions. Only $13.3 \%$ of subjects used to check urine and blood sugar at home, $26.7 \%$ used to take care of their feet and $4 \%$ used to carry the sugar or biscuit and water during the travelling to avoid hypoglycaemic spells. For most of them, the main concerns were only their curative treat ment. Similar findings were observed in many studies. In the cross-sectional study[6] conducted at Chandigarh of the 60 diabetic individuals 48 subjects knew that sweets and fatty foods should be avoided but only $18.3 \%$ were avoiding them, monitoring of blood sugar was poor $(46.7 \%)$, and none of the patients knew about self therapy.

In the study[7] conducted in 150 diabetic residents of Pondicherry most of the patients were aware of the need for dietary care or medication, but only $50 \%$ mod ified their diet. Of the $97 \%$ using anti-d iabetic agents, some were using them wrongly and only $10.6 \%$ of the subjects tested their urine, although $71 \%$ were aware of the need. None of the patients had any formal education regarding diabetes and only $34 \%$ consulted the physician regularly. Cross sectional study[8] done in Egypt in 2003 showed attitude of patients regarding different self care behaviours - nearly half of them paid frequent attention towards testing blood sugar (45.5\%), compliance to medications (51.3\%), diet $(41.5 \%)$ and exercise $(10.5 \%)$.

This study shows that, $104(34.7 \%)$ were taking treatment irregularly. Similar result was seen in a study conducted by Puria et al[9] at Urban Health Centre (UHC) of GMCH Medical College, Chandigarh in 273 known cases of type 2 diabetes where $28 \%$ patients were taking treatment irregularly. Reasons for irregular treatment in $28 \%$ were mainly failure to understand the importance of adhering to the treatment, lack of family support and expensive medicine. In a study[10] only seven respondents out of $611(1.1 \%)$ undertook home monitoring of blood glucose. Similar findings were noted in the CODI study[11] where only $6 \%$ of patients monitored their diabetes more than once a month. The rest monitored their diabetes once every two months or more $(48 \%)$, or once every three months or more $(47 \%)$.

Diabetic patients should examine their blood sugar once in three months, but this study shows that only $55(18.3 \%)$ subjects used to check their blood sugar once a month while $161(53.7 \%)$ subjects used to check sugar once in 3 months. Similar result was seen in study by Kapur et al[12] that showed only 6 per cent of patients monitored their diabetes more than once a month. The rest monitored their diabetes once every 2 months or more or once every 3 months or mo re $(47 \%)$. Both life style and self care were improved after interventions which are important parameters to control diabetes.

Present study shows that regular health education about diabetes can help to controlb lood sugar with in normal range. Significant decrease in mean fasting and post-prandial blood sugar was there from pre intervention to post intervention phase. Similar results were seen in a study[13] carried out in Iran to assess the effectiveness of dietary education in reducing plasma glucose levels in patients with type 2 diabetes. It was found that, the intervention group lost $1.5 \pm$ $2.2 \mathrm{~kg}$ as against a weight gain in the control group of $0.5 \pm$ $2.3 \mathrm{~kg}$. Fasting plasma glucose decreased $21 \pm 55 \mathrm{mg} / \mathrm{dl}$ in the intervention group and increased $19 \pm 78 \mathrm{mg} / \mathrm{dl}$ in the control group. Glycosylated haemoglobin decreased $1.9 \pm$ $2.1 \%$ in the intervention group and $0.2 \pm 2.2 \%$ in the control group. In a study[14] of 165 diabetic patients who received outpatient diabetes education for one week showed a significant increase in the knowledge score, which was associated with a significant fall in $\mathrm{HbAlc}$ at 6 months. Hawthorne et al in his eleven trials[15] in 2008 involving 1603 people, showed an improvement in Glycemic control (HbA lc), fo llowing health education at three months [weight mean difference (WMD) - $0.3 \%, 95 \%$ CI -0.6 to -0.01$]$, and at six months (WMD -0.6\%, 95\% CI -0.9 to -0.4), co mpared with control groups who received 'usual care'. This effect was not significant at 12 months post intervention (WMD $-0.1 \%, 95 \%$ CI -0.4 to 0.2 ). Knowledge scores also imp roved in the intervention groups at three months (standardized mean difference (SMD) $0.6,95 \%$ CI 0.4 to 0.7 ), six months (SMD 0.5, 95\% CI 0.3 to 0.7) and twelve months (SMD 0.4, $95 \%$ CI 0.1 to 0.6$)$ post intervention. Similarly the six-year prospective study[16] showed that after two years of intervention $59 \%$ of the patients proved well controlled. In "Modena Diabetes Project"[17] after four years follow-up, the individual before/after match-paired outcomes revealed an improvement in Glycemic control: $\mathrm{HbAlc}$ levels significantly decreased to $7.39+/-1.31 \%$, and the percentage of patients with $\mathrm{HbAlc}$ level of $<6.5 \%$ significantly increased from $15.7 \%$ to $22.1 \%$. There was also a significant decrease in body weight (from $78.3+/-14.8$ to $77.6+/-$ $14.6 \mathrm{~kg}$ ) and BMI (from $28.8+/-4.8$ to $28.5+/-4.9 \mathrm{~kg} / \mathrm{m} 2$ ).

In a large US-based cohort study[18] by Karter et al which included 24,312 patients with type 1 and type 2 diabetes, $\mathrm{HbAlc}$ was lower in patients who regularly did SMBG. Satpute et al in their study[19] assessed the impact of patient counselling, Nutrition and Exercise in 35 patients with Type-2 Diabetes Mellitus. Glycosylated haemoglobin (HbAlc), Fasting plasma glucose, PPG (Post-prandial Glucose), total cholesterol, trig lyceride, HDL (High Density Lipoproteins), LDL (Low Density Lipoproteins) and BMI were measured at baseline and the end of the study. It was shown that glycemic control of type-2 diabetic patients can be improved through patient counselling regarding disease, medication, diet and exercise. In a study[20] done to determine the effects of a culturally competent diabetes 
self-management intervention in Mexican Americans with type 2 diabetes, experimental groups showed significantly lower levels of $\mathrm{HbA} 1 \mathrm{c}$ and fasting blood glucose at 6 and 12 months and higher diabetes knowledge scores. At 6 months, the mean $\mathrm{HbAlc}$ of the experimental subjects was $1.4 \%$ below the mean of the control group. This study confirms the effectiveness of culturally competent diabetes self-management education on improving health outcomes.

One of the routine in-house studies[21] conducted to assess the quality and benefits of education at M.V Diabetes Specialties Center, The study revealed that awareness of glucometer was significantly higher among those who attended the education programme. $38.6 \%$ changed their exercise pattern after attending the education programme. When the patients were assessed regarding their knowledge of diabetes and its actual practice (dietary practice, compliance, home monitoring) the intervention group showed a significant and greater improvement in the knowledge of the disease and self-care and in the dietary practice.

The results of another study[22] conducted in Netherland in which follow up was done after 12 months, indicated that primary care programs which integrated education into structured care were able to improve both the type 2 diabetic patient's knowledge about the disease and their self care behaviour. In a study[11] done in Gujarat Refinery Hospital, Vadodara, it was found that quarterly health and nutrition education program for diabetics decrease blood sugar, weight and total fat intake.

Chandalia et al[23] ass essed the nutritional knowledge and control of diabetes in 43 non-ketos is-prone diabetic subjects. The patients were exposed to a 1-h nutritional counselling program in groups of three to five. It was observed that the patients' nutritional knowledge and the control of diabetes improved significantly after counselling in those patients in whom control had been inadequate.

In this study mean blood sugar of patients doing regular physical exercise was less than others. Meta analys is [24] of effects of different modes of exercise training on glucose control done by Snowling and Hopkins, concluded that aerobic, resistance and combined exercise have small to moderate beneficial effect on glucose control in type 2 diabetic patients. Study[25] done by Nield et al to assess the effects of different types of dietary advice through weight change in people with type 2 diabetes, and the effects of dietary advice plus other lifestyle interventions (i.e. exerc ise, behavioural approaches) through weight change in people, appears to improve glycated haemoglobin at six and twelve months in people with type 2 diabetes. In a study conducted in Copenhagen[26-28] showed the group-based diabetes rehabilitation programme consisting of empowerment-based education, supervised exercise and dietary intervention had better short- and long-term glycaemic outcomes than the traditional best practice for individual lifestyle counselling in a diabetes outpatient clinic setting. Jie $\mathrm{Hu}$ in his study[29] found that age, BMI, Nutritional health and physical exercise significantly predict the quality of life in Diabetic patients.
From the above observations we found that Health \& Nutrition Education are important intervention measure to control blood sugar, modify the diet and life style and improve the self care practices.

\section{Conclusions}

People have to be educated through mass media on Diabetes and its risk factors. The health workers have to play part by educating the people and also themselves being an example in avoiding the risk factors for diabetes like consumption of food having high glycemic index, alcohol etc. People have to be educated on the importance of regular physical exerc is es and have to be encouraged to do the same.

\section{REFERENCES}

[1] Wild S, Roglic G, Green A, Sicree R, King H Global Prevalence of Diabetes: Estimates for the year 2000 and Projections for 2030. Diabetes Care 2004;27(5):1047-1053.

[2] Diabetes Mellitus. In: K.Park's, Textbook of Preventive and Social Medicine. M/s Banarsidas Bhanot Publication, Jabalpur, 20th Edition 2009:341-344.

[3] Ramachandran A, Snehalatha C, Kapur A, Vijay V, Mohan V, Das AK, et al. Diabetes Epidemiology Study Group in India (DESI). High prevalence of diabetes and impaired glucose tolerance in India: National Urban Diabetes Survey. Diabetologia 2001; 44:1094-101.

[4] Kapur A, Shishoo S, Ahuja MMS, Sen V, Mankame K. Diabetes Care in India - Physicians' Perceptions Attitudes and Practises (DIPPAP - 1 Study). Int J Diab Dev Countries 1997; 17:2-12.

[5] R Gupta, Priyanka Rastogi, M Sharma, VP Gupta, SK Sharma, K Kothari. BMI, waist size, waist hip ratio and cardiovascular risk factors in urban subjects. JAPI 2007; 55: 621-627.

[6] Kaur K, Singh MM, Kumar, Walia I. Knowledge and self-care practices of diabetics in a resettlement colony of Chandigarh. Indian J Med Sci 1998; 52:341-7.

[7] Gopalan R, Srinivasa DK, Dasgupta B. Perceptions \& practices of diabetics in Pondicherry. Indian $\mathrm{J}$ Med Res 1991;94:30-5.

[8] Mohammed HK, Mosleh AI, Abdel RED, Khattab MS. Predictors of Self-Care Behavior in Adults with Type 2 Diabetes Mellitus in Abu Khalifa Village-Ismailia-Egypt. Suez Canal Univ Med J 2003 Oct;6(2):185-95.

[9] Puria S, Kalia M, Mangat C, Goel N, Abhimanyu, Swami H. Profile Of Diabetes Mellitus In Elderly. The International Journal of Geriatrics and Gerontology . 2008;4:14-18.

[10] Rayappa PH, Raju KNM, Kapur A, Bjork S, Sylvist C, Dilip Kumar KM. The impact of socio-economic factors on diabetes care. Int J Diab Dev Countries 1999, 19:7-16.

[11] Kapur A. Influence of socio-economic factors on diabetes care: Cost of diabetes in India - The CODI study. Int J Diab Dev Ctries 2001; 21:77-85. 
[12] Kapur A, Bjork S, Nair J, Kelkar S, Ramachandran A. Socioeconomic determinants of the cost of diabetes in India. Diabetes Voice 2004;43:18-21.

[13] Shabbidar S, Fathi B, Shirazifard NM. Effects of clinical nutrition education on glycemic control outcomes in type 2 diabetes. Int J Diab Dev Ctries 2006;26(4):156-59.

[14] Shah JH, Murata GH, Duckworth WC, Hoffman RM, Wendel CS. Factors affecting compliance in Type 2 diabetic patients: Experience from the Diabetes Outcomes in Veterans Study (DOVES). Int J Diab Dev Ctries 2003; 23:75-82.

[15] Hawthorne K, Robles Y, Cannings-John R, Edwards AGK. Culturally appropriate health education for type 2 diabetes mellitus in ethnic minority groups (Review) Cochrane Database of Systematic Reviews 2008;3.Art. No:CD006424. DOI: 10.1002/14651858.CD006424.pub2.

[16] Gyimesi A, Bányai T, Dudás M, Pocsay G, Sajti I, Iványi J. Six-year follow up on recently diagnosed NIDDM patients. Orv Hetil 1995 Apr 2;136(14):699-702.

[17] Ciardullo AV et al. Changes in long-term glycemic control and performance indicators in a cohort of type 2 diabetic patients cared for by general practitioners: findings from the "Modena Diabetes Project. Nutr Metab Cardiovasc Dis. 2003 Dec;13(6):372-6

[18] Karter AJ, Ackerson LM, Darbinian JA, et al. Self-monitoring of blood glucose levels and gly cemic control: the Northern California Kaiser Permanente Diabetes registry. Am J Med 2001;111(1):1-9.

[19] Satpute DA, Patil PH, Kuchake VG, Ingle PV, Surana SJ, Dighore PN. Assessment of impact of Patient Counselling, Nutrition and Exercise in patients with Type 2 Diabetes Mellitus. International Journal of PharmTech Research ISSN : 0974-4304 2009 Jan - March;1(1):1-21.

[20] Brown SA, Garcia AA, Kouzekanani K, Hanis CL. Culturally competent diabetes self-management education for Mexican Americans: the Starr County border health initiative. Diabetes Care 2002 Feb;25(2):259-68.

[21] Asha A, Pradeepa R, Mohan V. Evidence for Benefits from Diabetes Education Program. Int $\mathrm{J}$ Diab Dev Ctries 2004;24:96-102
[22] Van den Arend IJ, Stolk RP, Rutten GE. Education integrated into structured general practice care for Type 2 Diabetic patients results in sustained improvement of disease knowledge and self-care. Diabetic Medicine 2000;17:190-7.

[23] Chandalia HB, Bagrodia J. Effect of nutritional counseling on the blood glucose and nutritional knowledge of diabetic subjects. Diabetes Care 1979;2:353-6.

[24] Snowling MJ, Hopkins WJ. Effects of different mode of exercise training on glucose control and risk factors for complication in type 2 diabetic patients: A Meta analysis. Diabetes Care 2006;29:2518-27

[25] Nield L, Moore HJ, Hooper L, Cruickshank JK, Vyas A, Whittaker V, Summerbell CD. Dietary advice for treatment of type 2 diabetes mellitus in adults Cochrane Database of Systematic Reviews 2007;3:CD004097.DOI:10.1002/14651 858.CD004097.pub4.

[26] E.S. Vadstrup, A Frolich, H Perrild, E. Borg and M. Roder, "Effect of group based rehabilitation programme on Glycemic control and cardiovascular risk factor in Type 2 Diabetes Mellitus patients: the Copenhegan Type 2 Diabetes Rehabilitation Project" Patient education and counseling, vol.84, no. 2, pp. 185-190, 2011

[27] Ramune Jacobsen, Eva Vadstrup, Michael Roder, Anne Frolich, "Predictors of effects of lifestyle intervention on Diabetes Mellitus Type 2 Patients" The Scientific world Journal Volume 2012 (2012), Article ID 962951, Doi: $10.1100 / 2012 / 962951$

[28] Eva S Vadstrup, Anne Frølich, Hans Perrild, Eva Borg and Michael Røder, "Lifestyle intervention for type 2 diabetes patients - trial protocol of The Copenhagen Type 2 Diabetes Rehabilitation Project" BMC Public Health 2009, 9:166 doi:10.1186/1471-2458-9-166

[29] Jie Hu, Debra C. Wallace, Anita S. Tesh, "Physical Activity, Obesity, Nutritional Health and Quality of Life in Low-Income Hispanic Adults With Diabetes" Journal of Community Health Nursing. 2010, Volume 27 (2): 70-83. DOI: $10.1080 / 07370011003704933$ 